Forthcoming in Truth and Speech Acts: Studies in the Philosophy of Language. Eds. G. Siegwart and D. Greimann (Routledge)

\title{
Truth as a Normative Modality of Cognitive Acts
}

\author{
Gila Sher and Cory D. Wright
}

If I am right, the idea that there can be an account of truth which has 'nothing to do with the mental' is an illusion.

- Hilary Putnam, Representation and Reality

\section{Introduction}

Attention to the conversational role of alethic terms seems to dominate, and even sometimes exhaust, many contemporary analyses of the nature of truth. Yet, because truth plays a role in judgment and assertion regardless of whether alethic terms are expressly used, such analyses cannot be comprehensive or fully adequate. A more general analysis of the nature of truth is therefore required-one which continues to explain the significance of truth independently of the role alethic terms play in discourse. We undertake such an analysis in this paper; in particular, we start with certain elements from Kant and Frege, and develop a construct of truth as a normative modality of cognitive acts (e.g., thought, judgment, assertion). Using the various biconditional T-schemas to sanction the general passage from assertions to (equivalent) assertions of truth, we then suggest that an illocutionary analysis of truth can contribute to its locutionary analysis as well, including the analysis of diverse constructions involving alethic terms that have been largely overlooked in the philosophical literature. Finally, we briefly indicate the importance of distinguishing between alethic and epistemic modalities.

\section{On the locutionary significance of alethic terms}

Several contemporary analyses - scions of earlier alethic theories having taken the linguistic turn - are renowned for affixing their gaze on the function or role of the term 'true' in the standard English predicate 'is true.' The explanatory task, according to such analyses, is one of spelling out what it is that speakers are saying when they use, mention, or ascribe this term in natural language. One example is Grover's (1992) prosentential theory, which develops a grammatical analysis of the concept of TRUTH whereby all ordinary truth talk ultimately can be explained in terms of the prosentential roles occupied by the two anaphors 'true' and 'false.' For Grover, the locutions 'it is true' and 'that is true' are the paradigmatic expressions of the role of truth in English, functioning as generalizations with respect to sentence positions. Brandom (1994; see also Brandom 2002) gives a similar analysis that uses the operator schema, 
it is true that $p$ iff $p$,

to emphasize the prosentential role of alethic terms, but one that, because of subtle difficulties with the initial formulations of the prosentential theory, treats truth as a prosentence-forming operator functioning anaphorically with regard to antecedent sentence tokens. The deflationary version of minimalism espoused by Horwich (1990) certainly constitutes another. Horwich alleges that explaining the function or role of the standard truth predicate simply requires using the equivalence schema,

(2) the proposition that $p$ is true iff $p$,

to demonstrate that truth is merely an endorsement device existing simply for the sake of a few logical and conversational needs (facilitating certain generalizations and anaphoric references such as 'almost everything Camus thought is true' and 'Köhler's thesis is true,' providing an austere alternative to substitutional quantification, etc.). He concludes that, "All uses of the truth predicate are explained by the hypothesis that its entire raison d'être is to help us say things about unarticulated propositions, and in particular to generalize over them" (Horwich 1990: 126-27). In the main, then, these and other analyses purport to explain the nature of truth by specifying the grammatical patterns in which the standard truth predicate expressing the concept TRUTH occurs. ${ }^{1}$

The significance of alethic terms attended to on these overtly locutionary analyses is, to be sure, an important aspect of investigating the nature of truth; but there are at least two main reasons why such analyses are incomplete. First, attention to the function or role of the standard truth predicate is typically had at the expense of attention to 'truth talk' more generally, to the point where it has become curiously fashionable for contemporary analyses to neglect the full range of alethic terms and expressions used in natural language. What makes it curious is that the lexical category for which explanations of the locutionary significance of alethic terms purport to account for is far more complex than can be captured in an analysis solely of the default predicate 'is true.' That this predicate is a basic alethic locution in English neither delimits the explananda for which theories of truth are constructed, nor rules out the import of other predicates and cognates for investigating the concept of TRUTH. Moreover, numerous constructions beyond prosentential anaphors or instances of the equivalence schema are explanatorily relevant - such as instances of an adverbial schema,

$$
\text { truly } p \text { iff } p
$$

- but about which nothing can be said using only the resources of analyses with such a narrow attention span. Other examples might include a range of idioms, conceptual blends, metaphors, and so forth: 'truth is stranger than fiction,' 'truth is the first casualty of war,' 'lying is truly despicable,' 'truly you can't mean that,' 
'the truth shall set you free,' 'bicycle wheels need frequent truing,' 'if bicycle wheels can be trued, so can conceptual schemes,' 'the approximate truth of that theory will be good enough for our purposes,' 'may all of your dreams come true,' 'tried and true,' 'there's a kernel of truth in every stereotype,' 'stretching the truth is not being true to the facts,' 'being true to yourself means showing your true colors,' 'en la luz de la verdad' and so on. ${ }^{2}$ All such expressions contribute to the organization of the lexical category, and therefore constitute data that ultimately must be accounted for.

Yet, in contemporary philosophical analyses, one almost never sees a principled reason being offered for why these other predicates and expressions do not synergistically contribute to our understanding of the lexical semantics of alethic terms, or why an adequate analysis of the canonical use of 'true' is thereby a comprehensive one. Indeed, any partitioning of the explananda that yields a single paradigm of alethic locutions will prove only to be a partial analysis, and will be unable to adequately determine how alethic terms are conceptualized by competent speakers of natural languages. Methodologically, of course, it makes sense to break up the problem of analyzing the nature of truth into smaller, more manageable problems; but it should be kept in mind that solving one such smaller problem does not exhaust the entire investigative enterprise, and we should be chary about winnowing stipulations or assumptions to the effect that the predicate 'is true' - insofar as it denotes a property of truth-bearers (the nature of that property being an open question) - is all that a theorist ever need be concerned about. Consequently, a comprehensive analysis of the concept of TRUTH, and the semantics of alethic terms for expressing it, would need to take into account the full range of uses and meanings to which that concept is put.

The second reason - and the one which we will focus on in this essay - is that, since the concept of TRUTH is always already (to borrow a phrase from Heidegger) operative in thought and judgment, it cannot be entirely captured by an analysis of the conversational function or role played by the alethic terms used to express that concept in language. Frege made heavy weather of just this point, remarking that, "We cannot recognize a property of a thing without at the same time finding the thought this thing has this property to be true" (Frege 1918/1977: 5-6). To this he adds the point that applications of alethic locutions to declarative sentences are unnecessary for the expression of truth.

We express acknowledgement of truth in the form of an assertoric sentence. We do not need the word 'true' for this. And even when we do use it the proper assertoric force does not lie in it, but in the assertoric sentence-form; and where this form loses its assertoric force the word 'true' cannot put it back again. This happens when we are not speaking seriously. ... In poetry we have the case of thoughts being expressed without being actually put forward as true, in spite of the assertoric form of the sentence. ... Therefore the question still arises, even about what is presented in the assertoric sentence-form, whether it really contains an assertion. And this question 
must be answered in the negative if the requisite seriousness is lacking. It is unimportant whether the word 'true' is used here. This explains why it is that nothing seems to be added to a thought by attributing to it the property of truth.

(Frege 1918/1977: 8)

Frege's prose nicely articulates why truth's function or role with regard to cognition does not coincide with the use of lexical items expressing alethic concepts, and thus why overtly locutionary treatments are insufficiently general to the extent that they purport to be explanatorily adequate. This passage also alludes to the import of illocutionary force in the expression of truth, suggesting the illocutionary role played by the assertion of a proposition's truth is tantamount to the role played by the assertion of that proposition. ${ }^{3}$ As Frege avers, the form of sentential sense, and the seriousness with which it is asserted, are each necessary and jointly sufficient for the expression of truth. Consequently, an understanding of what the relationship between truth and normativity consists in can proceed by foregoing the sorts of locutionary treatments common in contemporary analyses. And this approach may even generalize beyond illocutionary treatments, for truth plays an indispensable role in that which assertions and assertions of truth are manifestations of - i.e., cognition more generally.

So, whereas the first reason warns against underemphasizing the wide variety of uses and meanings that contribute to the ways in which truth is conceptualized, the second reason warns against overemphasizing the locutionary significance of alethic terms. Theorists should search for a more general analysis of the nature of truth - one that also attends to the significance of truth in cognition - regardless of whether any alethic locutions are explicitly involved. We undertake such an analysis of truth in this paper, developing the construct of truth as a particular normative modality of certain cognitive acts. The germ of this construct takes root in the works of Kant and Frege. For Kant, truth is a modality of judgment, whereas for Frege, it is a norm of judgment. We will begin with these two authors in order to extract elements from each and thus formulate our own analysis.

\section{Kant's analysis of truth as a modality of judgment}

Insofar as the 'positive' or 'material' nature of truth was discussed at all in The Critique of Pure Reason, it was done so within a distinctly cognitive dimension. The bearer of truth is a particular cognitive state or type of thought, the judgment: "Truth ... is not in the object, insofar as it is intuited, but in the judgment about it, insofar as it is thought" (A293/B350). Further, judgments aim to bear truth, such that truth is a target of one of three modalities of judgment, the assertoric modality. Kant wrote, "Assertoric judgments are those where the affirmation or negation is considered as actual (true)" (A75/B100; emphasis ours), and again, "An assertoric proposition speaks of logical actuality or truth" (A76/B101; emphasis ours). Other points made by Kant included: (i) The concept of TRUTH is the concept of a correspondence notion (A58/B83), (ii) A general criterion of truth 
(in the sense of a test that determines, with respect to every 'cognition,' whether it is true or false) is impossible (A59/B83), and (iii) Correspondence is restricted to agreement with the realm of phenomena (A489/B517). ${ }^{4}$ Yet, while Kant's explicit characterization of truth was quite minimal, his analysis received rich and substantive content from his account of the structure of human cognition, its relation to reality, and its culmination in judgments of truth in the assertoric mode. Roughly, and somewhat selectively (given the limited role Kant's views play in our project), we construe Kant's cognitive analysis of truth along the following lines.

3.1. Judgment. As both the fundamental bearer of truth and the culmination of cognitive states, judgments were a crucial pivot of Kant's analysis of the nature of truth. He referred to these acts of information-processing as the "mediate cognition of an object, that is, the representation of a representation" (A68/B93). As unifying functions among distinct representations, judgments synthesize cognitions by bringing them together under a common, intelligible, and discursive format, such that, for any given series of representations, there is a higher-level representation by which that series can be synthesized. This cognitive dimension allows the concept of TRUTH to be inextricably bound to the concept of MODALITY by which all judgments are formatted. To a first approximation then, the Kantian analysis of truth is an analysis of the mode by which judgments process the information constituted by the relation of agreement between two corresponding relata - wherein a particular type of cognition is related aright to the world of objects and events - and by which judgments consequently can bear truth.

3.2. Cognition. Kant's use of the term 'cognition,' or 'cognitive state,' denoted that which consists in a determinate relationship between what is given in receptivity and its conceptualization as understood in acts of spontaneity (A19/B33; A50/B74). In its most basic structure, this determinate relationship is representational, where a representation is simply a generic constituent of cognition that codes for representational content - that is, something that can minimally factor in cognition, in the composition of percepts and concepts.

Judging truly about how things are in the world presupposes and requires recognition of the world of objects, and it goes without saying that Kant believed cognition to be a product of exactly two types of cognitive capacities - receptivity and spontaneity, perception and conception. ${ }^{5}$ For Kant, each cognitive capacity was equally important: "It is just as necessary that we make our concepts sensible as it is necessary that we make our intuitions understandable" (A51/B75). Yet, while neither capacity had any special significance over the other, there was a priority, a non-temporal succession, to their activities in producing cognition. First, representational content - the matter of sensation - is presented to anatomical complexes of sensory modalities (e.g., olfaction, vision, audition, equilibrium), which collectively operate as the multimodal capacity of receptivity. The sensation itself, or sensible intuition, is the effect that such content has on these sensory modalities when it is passively taken up by cognizers (i.e., given), 
and the manner in which it is taken up in passive receptivity is determined by the spatio-temporal forms that structure sensible intuitions into percepts. To be sure, percepts are representations of the Phenomenal realm as it appears, such that any correspondence of cognitions must be to empirical objects. While what is given in receptivity is indirectly connected to things-in-themselves, it was also a hallmark of Kant's philosophy that the Noumenal realm is uncognizable, in which case, 'objective states of reality' must be those states of reality wherein 'objects' become cognizable. On Kant's analysis, the nature of truth as correspondence was therefore restricted to the world of appearances (although, a complete understanding of his analysis may require an explanation of the contributions of the Noumenal realm in acts of judging truly). Second, through the capacity of spontaneity, the understanding of a cognizer collects the sensible intuitions under concepts by means of functions. 'Functions' are basic units of epistemic activity, i.e., acts of information-processing that unify distinct representations under a single representation; 'concept' refers to those general representations that are actively conceived of, or thought by, the understanding, and that can be reapplied to different objects in virtue of their generality. The concepts thought by the understanding in acts of spontaneity stand in mediate relations to representational content, unlike intuitions or percepts, which stand in immediate relations to the particulars that they represent (A19/B33, A320/B377). Importantly, it is only here - in the union of percepts structured by the forms of sensible intuition, and of concepts - that 'objects' per se can properly begin to be referred to. That is to say, it is only at the stage of conceptual synthesis that the possibility of truth first arises.

3.3. Truth. To better comprehend Kant's conception of truth as a modality of judgment, we take the opposite direction to that taken by Kant himself; that is, we follow the constructive, rather than the analytic, order of his account of cognition, starting with the construction of conceptual representations of objects, and concluding with the construction of modally-formatted judgmental representations. This requires a progression from the account of cognition as conceptual synthesis of intuitions to the table of categories with its modal category of existence, ending with judgmental synthesis and the table of the logical functions of judgments - and, in particular, with the connection between assertoric modality and truth.

For Kant, the synthesis of cognition was a rule-governed process, implying that the unification of representations cannot be a 'mere association of ideas' since unified representations must stand in determinate relations to what they represent if they are not to be 'accidental heaps' of ideas (A121). Consequently, in order to specify how the understanding collects sensible intuitions under concepts by means of increasingly complicated judgmental syntheses, a more determinate relation than mere association would need to be presupposed - one which unifies representations by means of the understanding's use of further, more general concepts. 
The most general concepts are the 'pure concepts of the understanding,' the twelve prefixed categories, which Kant took to be necessary a priori conditions on the possibility of cognition in general. In every re-cognition of objects through synthesis, the unification of distinct representations implicates some of the categories. Syntheses via the categories occur in at least one of four ways: quantitatively, qualitatively, relationally, and modally. The first three types of synthesis each contribute to the identity of the objects represented. For example, objects may be a unity, plurality, or totality; their reality may be affirmed or denied; they may have intrinsic or contingent properties, stand in causal relations, etc. The fourth group of categories concerns the modal status of objects - their possibility, existence, or necessity (along with their complements). For Kant, the terms expressing the modal categories are not 'real predicates'; rather, they function logically as the copula of a subject-predicate judgment, and do not 'amplify' or unpack the concept of the subject. Hence, predications of possibility, existence, and necessity merely affect how objects are represented, not what those representations are of. As he put it,

The categories of modality have the peculiarity that, in determining an object, they do not in the least enlarge the concept to which they are attached as predicates. They only express the relation of the concept to the faculty of knowledge. Even when the concept of a thing is quite complete, I can still enquire whether this object is merely possible or is also actual, or if actual, whether it is not also necessary. No additional determinations are thereby thought in the object itself; the question is only how the object, together with all its determinations, is related to understanding and its empirical employment. (A219/B266)

According to Kant then, 'existence' does not denote a property inherent in objects. The question of existence concerns only whether the object can "be so given to us that the perception of it can, if need be, precede the concept" (B272). Existence is, however, a generalization of the postulate of actuality, which he characterized as follows: "[T]hat which is bound up with the material conditions of experience, that is, with sensation, is actual" (A218/B266). Rather than requiring that objects actually be perceived in order for them to be conceived as existent, this postulate only requires that cognizers be able, in principle, to connect the object with such a perception according to the appropriate rules.

The characteristics of the modal category of existence are reflected in the corresponding logical function of the assertoric modality of judgment, which, in addition to the problematic and apodeictic modalities, is one of the three ways by which cognitive acts of judging are formatted. The logical function referred to by 'problematic' modality ranges over those judgments that are logically possible or 'optional,' i.e., representations are assembled in such a way as to be noncontradictory. Problematic judgments, for Kant, typically served as the antecedents of conditionals or the disjuncts of disjunctive judgments; consideration of their truth or falsity is deferred or "suspended" because their 
affirmation or negation is only put forth as merely possible. ${ }^{6}$ The logical function referred to by 'assertoric' modality is the function of taking-to-be-true (Fürwahrhalten). It ranges over those judgments whose affirmation or negation is construed as actual or true, i.e., the suspension of consideration of truth-value is lifted. Finally, the logical function referred to by 'apodeictic' modality arises from the union of the previous two, ranging over those judgments whose possibility implies their truth, i.e., over necessary judgments. Together, these three logical functions belong to the modal 'moment of thought' - one of four superordinate, a priori, organizing principles by which the twelve logical functions of judgment are grouped (A70/B95; A76/B101). As with the modal categories, Kant singled out these logical functions of judgments for their 'peculiarity' (A74/B100; A219/B267); their special status consists in the fact that they are purely formal, abstracting away from all representational content, or conversely, in the fact that, just as conceptual content is not affected by the modal categories, judgmental content is not affected by these functions. " As Kant put it, "The modality of judgments is a quite peculiar function. Its distinguishing characteristic is that it contributes nothing to the content of judgment ... but concerns only the value of the copula in relation to thought in general" (A74/B100). As the purely formal group of logical functions, Kant's concept of MODALITY concerns the manner in which the assembly of representations in a given judgment is related to 'thought in general,' which might be understood as the conditions on the possibility of the understanding's deployment of cognition.

Again, of these three logical functions, the assertoric mode is the mode by which judgments serve as bearers of truth. Kant was not, of course, using the term 'assertoric' in the contemporary sense of the performance of an illocutionary act (e.g., promising, demanding), but in the sense in which such judgments are takings-to-be-true: in virtue of being the kind of subjective cognitive state that bears truth, judgments - as the culmination of the process of unifying representations into a higher-order representation - are related to (or better, may 'agree' with) the objective states of reality that make them true. In taking the form of a judgment in the assertoric mode, these higher-order representations are no longer a mere re-cognition of objects. They become a way of assaying the existence of objects and the properties possessed by them, and thus a way of (literally) capturing the truth of the matter (assuming that the assay is veridical). Consequently, judgments in the assertoric mode are true if extant objects are recognized to be as they actually are (Kant 1800/1992: 40); that judging truly concerns the existence of pure or empirical objects of sensible intuition (B110) is built into the logical function of the assertoric mode.

3.4. Correspondence. An important aspect of Kant's analysis of truth as a modality of judgment now comes into relief: correspondence. Kant's analysis regarded cognition as a process that begins with the stimulation of sensory modalities by something external and independent of them, proceeds to the conceptual construction of an external world replete with objects and properties, and culminates in the construction of judgments in the assertoric mode that allows 
complexes of external objects and the properties they possess to be represented as actual, as being the way that they actually are. This pairs the re-cognizance of extant objects with the extant objects re-cognized, which can yield 'agreement' insofar as the cognition is synthesized in the assertoric mode and the judgment is veridical, and thus brings out the connections between correspondence and actuality in the Kantian analysis of truth as a modality of judgment. Note that there is no question here of either a simple "isomorphism" or "mirroring" relation between language and reality. The structural relation between true judgments and the world is a highly complex relation, and the nominal definition of truth as the agreement of cognition and object confers substantive content insofar as it is filled in by Kant's account of information processing that leads from sensible intuitions and percepts to the conceptual representations of objects, and further progressing to judgmental syntheses carried out in the assertoric mode. As such, wherein Kant's analysis of truth is committed to existence and actuality in the relationship between cognitions and objects, it emerges as a genuine endorsement of the correspondence theory. ${ }^{8}$

While much more remains to be said about the place of the concept of TRUTH in Kant's analysis, we hope that what we have said here will suffice to give the reader some idea of the Kantian roots of our own account of the construct of truth as a modality of cognitive acts.

\section{Frege's analysis of truth as a norm of judgment}

There is a significant overlap between Kant's and Frege's views on the nature of truth, and there is much to be said about both Frege's Kantian inheritance and his criticisms of Kant. We will, however, minimize our attention to such comparison, since doing otherwise might overshadow our interest in an important dimension of Frege's analysis that he brought to the fore, which was all too quiescent in Kant: the normativity of truth.

4.1. Thought and Judgment. Frege maintained that truth is often mistakenly ascribed to sentences: "And when we call a sentence true we really mean that its sense is. From which it follows that it is for the sense of a sentence that the question of truth arises in general" (Frege 1918/1956: 292). The proper bearers of truth, then, are sentential senses. Frege named the senses expressed by these sentences 'thoughts,' and construed them as immaterial objects identifiable by their thinkable content; thoughts that do bear truth were, for him, semantically equivalent with 'facts.' The upshot is simply that truth is predicated of some thoughts expressed by some sentences (not all thoughts will turn out to be true or false). As he put it, just those thoughts are truth bearers that "can become ... judgment[s]," and while the bearers of truth are thoughts, the mere expression of a thought is different from, and independent of, the "laying it out as true" (Frege 1879/1967: 12).

Frege recognized a class of various cognitive acts, which are interrelated through 
the concept of TRUTH, and which get parlayed into a trichotomy in Der Gedanke. He wrote, "We distinguish: (1) the grasp of a thought - thinking, (2) the acknowledgement of the truth of a thought - the act of judgment, (3) the manifestation of this judgment - assertion" (Frege 1918/1977: 7). Accordingly, this suggests that cognizers first think, i.e., apprehend a possible thought whose content is something that subsequently can be judged. This initial stage - the grasping of a thinkable content - is associated with what Austin and others later referred to as a 'rhetic act,' or rhêsis - the execution of a cognitive act whose semantic value does not necessarily track veridicality and whose sense and reference are manifest in utterance. The judging of a thinkable content is itself a type of thinking, but one wherein the apprehension of a thinkable content coincides with the recognition of that content as being true. Lastly, the cognitive processes of thinking and judging thoughts terminate in the illocutionary act of assertion, which Frege construed as the manifestation of judgment. This terminus - either with or without alethic locutions - is something over and above thinkable contents and judgments thereof since it contains both without being identical to either.

It is frequently pointed out that 'judgment' - like 'thought' - exhibits a basic content/act ambiguity. On one hand, Fregean judgments are truth-bearing thoughts, the content of which has a certain factual status, i.e., "something which is either true or false" (Frege 1918/1977: 4). In this sense of 'judgment,' he treats them almost synonymously: "In fact I use the word 'thought' in approximately the sense which 'judgment' has in the writings of logicians" (Frege 1918/1956: 292). On the other hand, a Fregean judgment is a cognitive act, namely, the recognition of the truth of a thought (i.e., the re-thinking of a thought as being true, the grasping of a fact). As such, folks sometimes identify judgment with a cognitive state in the (empirical) psychological sense. Frege, however, did not identify judgment (or thought) in the sense of a cognitive act with judgment (or thought) in the empirical psychological sense, but consistently endeavored to keep these two senses distinct; indeed, it is difficult to overstate just how much this task held central sway in Frege's philosophy, especially in the larger context of insulating logic from psychology. He certainly held that judgments and thoughts in the sense relevant to his work are not cognitive states in the psychological sense; see Hornsby (2001: 663-65) and Woleński (2003: 184). Yet, Frege acknowledged that logic and psychology are both concerned with the relationship between judgment and truth, albeit in different ways: whereas logic investigates the truth of judgments in their normative capacity as justifying reasons, psychology investigates the causal determinations of judgments and reasoning - the 'subjective performance' of thinking truly, which stood outside of Frege's provenance.

4.2. Judgment-Stroke. Although Frege unequivocally posited thoughts as the proper or primary bearers of truth, the judgment-stroke and the nature of judgment also played an indispensable role in his investigation of the nature of truth, and garnered much of his attention. ${ }^{9}$ Indeed, in reflecting on the question, "What may 
I regard as the result of my work?" he commenced by mentioning the logical apparatus of the Begriffsschrift, but quickly reconsidered: "Strictly I should have begun by mentioning the judgment-stroke, the dissociation of assertoric force from the predicate" (Frege 1906: 184).

The Fregean concept of JUDGMENT entails that a thought's bearing truth requires a change in its status - from thinkable content to a content judged to be true - which therefore requires an operation performed on that thinkable content; the change in status that a thinkable content undergoes is symbolized by the 'judgment-stroke.' Now, for Frege, truth was not a property, so the judgment-stroke cannot predicatively add one to a thinkable content or an act of judging. The attribution of a property of truth, then, was not part of this change in status. What is added is some non-locutionary force attachable to the rhetic acts constitutive of those judgments.

There are at least two important interpretations of the judgment-stroke. On the first - held by Bell, Dummett, Wittgenstein, and others - where the judgmentstroke is absent, so too are both the cognizer's acknowledgment of the truth of a thinkable content, and its assertoric force. In the Begriffsschrift, he wrote, "If we omit the [judgment-stroke] ... the judgment will be transformed into a mere combination of ideas, of which the writer does not state whether he acknowledges it to be true or not" (Frege 1879/1967: 11). This and other remarks seem to indicate that the stroke is something of an epistemic operator - one that marks a cognizer's recognition and serious endorsement of the truth of a given thought as captured in its assertoric form. Subsequently, this way of interpreting the judgment-stroke partially maps it onto Kant's concept of JUDGMENT (-in-theassertoric mode, Fürwahrhalten). An alternative interpretation attempts to take seriously Frege's remark that the change in status from a thinkable content to a fact is a means of "advancing from the thought to the truth-value." It therefore rejects this mapping of Frege's judgment-stroke back onto Kant's concept of JUDGMENT (-in-the-assertoric mode), maintaining instead that it is a purely alethic operator signifying only the assertoric form of a thought, rather than any takingor holding-to-be-true: "The judgment-stroke is an operator whose primary linguistic function is to express a truth valuation of a thought: it expresses that the truth-value of a thought (or judgable content) is the True, not that the speaker internally judges the thought to be true" (Greimann 2000: 216); see also Ricketts (1996). Both interpretations tackle a very hard exegetical question, and have a good deal of plausibility to their credit; it is not part of our task here to adjudicate between them. We shall only suggest that the operation of the judgment-stroke is a mark enacted on a thinkable content as thought by a cognizer, and it stands to reason that the endorsement, in assertoric discourse, of that content as being true supervenes on that enacted operation.

4.3. Truth and Epistemic Context. Like Kant, Frege considered truth in an explicitly epistemic context: "What I have in mind is that sort of truth which it is the aim of science to discern" (Frege 1918/1977: 2). One result of this 
consideration is an identification of the basic situations involving truth and knowledge. The advancement from conjecture to knowledge, for example, is construed as advancement from thought to recognition of truth: "An advance in science usually takes place in this way: first a thought is grasped, and thus may perhaps be expressed in a propositional question; after appropriate investigations, this thought is finally recognized to be true. We express acknowledgement of truth in the form of an assertoric sentence" (Frege 1918/1977: 7-8).

This context of epistemic advancement also leads to a heightened awareness of the ever-present threat of error or mistake. For appending the judgment-stroke to a thinkable content is a cognitive act that requires a cognizer to open herself up to the possibility of being epistemically out-of-step with the world, a constant possibility that requires some norm to guide her. Frege writes,

By the step with which I win an environment for myself I expose myself to the risk of error. ... I cannot doubt that I have a visual impression of green but it is not so certain that I see a lime-leaf. So contrary to widespread views, we find certainty in the inner world while doubt never altogether leaves us in our excursions into the outer world. It is difficult in many cases, nevertheless, to distinguish probability from certainty here, so we can presume to judge about things in the outer world. And we must presume this even at the risk of error if we do not want to succumb to far greater dangers.

(Frege 1918/1956: 306)

Judging truly about the world is a goal-directed activity in the straightforward sense that judgments are directed toward, or aim at, the goal of re-cognizing things for what they are, and we may interpret Frege here as saying that the attendant possibility of error or mistake enables - or, perhaps even more strongly, that it necessitates - a norm or standard of knowledge and assertion. Truth is naturally construed as just such a standard.

4.4. Normativity and Logic. The relational property of being directed toward thus includes the sort of force that tightly connects truth and normativity; the connection emerges because cognitive acts such as judgment and assertion presuppose a certain orientation to the very environment that the Fregean cognizer wins for herself, an orientation which must be embraced and enacted. It is part of the concept of ORIENTATION that it involves a sort of "direction of fit," which is just to say that thinkable contents can capture the truth of the matter in better and worse ways. The world itself can be, or not be, the way in which a cognizer's judgment posits it as being; the world stands as a source of friction and regulation governing thinkable contents, and Frege's judgment-stroke notationally provides a vehicle for marking this 'direction of fit.' Hence, the stroke of a judgment, in the sense that it pertains to a re-cognition of a thought as true, is a normative stroke. Kant was not, of course, remiss on this point; however, in Frege's analysis, the goal-directed norm of re-cognizance that is inherent in his concept of JUDGMENT was made explicit. 
Frege, as we have just indicated, was interested in a concept of TRUTH that has epistemic - in addition to alethic - import, and in particular one that is the end of knowledge. The upshot of such a view is that Frege ushered in a strong, principled connection between truth, logic, and science - one which he took to be both normative and nomic:

To discover truths is the task of all sciences; it falls to logic to discern the laws of truth. ... Laws of nature are general features of what happens in nature, and occurrences in nature are always in accordance with them. It is $\ldots$ in this sense that I speak of laws of truth. Though in their case it is a matter of what is rather than of what happens. From the laws of truth there follow prescriptions about asserting, thinking, judging, inferring.

(Frege 1918/1977: 1)

So, just as science and epistemology aim at discovering the laws governing a particular domain of truth, logic aims at discovering the general laws that govern all domains of truth, i.e., the 'laws of truth,' which are universal, exceptionless prescriptions of thought. In other words, every science guides and constrains some domain of assertoric discourse; but logic guides and constrains all such domains. As Sher puts it, "The normative force of logic exceeds that of all other sciences. All systems of norms are bound by logic, but the logical norms themselves are bound by no other norms. Scientific methodology, ethics, jurisprudence, etc., are all subject to the authority of logic, but logic is not subject to theirs" (Sher 1999: 211). And this special status logic accrues due to what philosophers later referred to as its "strong invariance property," and what Frege characterized as its not distinguishing between particulars. Laws such as "Every object is identical with itself' (Frege 1893: 14) govern all objects, regardless of their differences, thereby constraining all assertoric discourse regardless of its subject matter. Subsequently, they constitute the most general standards of thinking truly: 'Don't think of object $\varphi$ as being different from $\varphi$,' 'Don't affirm $p$ while denying $\sim p$,' etc. As Woleński nicely points out:

Frege did not contrast theoretical and normative logic. In general, the normative is related to values, which always constitute a definite sphere of oughtness. Since truth is a value, logic, as dealing with the True, concerns this mode of normativity. Laws of logic are the principles of truth such that no thinking is possible without them.

(Woleński 2003: 182-83; emphasis ours)

\section{Truth as a normative modality of cognitive acts}

In order to move away from the trappings of an overtly locutionary treatment of the nature of truth, we have returned to Kant and Frege in order to retrieve a few elements from their respective analyses, and then exploit those elements for the purposes of pointing the way to an alternative, more general account. ${ }^{10}$ Together, 
their two analyses give us the elements needed for the working construct of truth as a normative modality of cognitive acts. ${ }^{11}$

First, Kant's analysis of truth (or more precisely, of being true as a relational property present in certain acts of judgment) offers an initial inroad into characterizing the concept of ALETHIC MODALITY. The term 'alethic' originates from the Greek alêtheia ( $\dot{\alpha} \lambda \eta \theta \varepsilon i \alpha, \alpha \dot{\alpha} \eta \theta \dot{\varepsilon} \varsigma)$ - which conjoins the alpha-privative with the root lethe - and has been taken to mean unforgetting (i.e., revealment, uncovering, or unveiledness with regard to truth); the term 'modality' is used derivatively from the root 'mode' and concerns the ways in which thinkable contents can be formatted, i.e., their status. A rude description of this concept might then be the way in which something is found to be or actually disclosed in cognition, or, in a more preferable idiom, the worldly orientation of a cognitive act (e.g., thought) which renders it a potential bearer of a truth-value. Kant construed the alethic modalities - and, in particular, the assertoric mode - as a group of logical functions that must be operative for any judgmental synthesis of cognitions to occur. In virtue of their formatting of higher-level representations in an alethic mode, judgmental syntheses allow the objects represented to be recognized, and thus function as bearers of truth. Further, insofar as it does track the truth, that selfsame formatted re-cognition of objects in judgment is tantamount to an ontic apprehension of the ways in which extant objects are in the empirical world.

Second, Frege's analysis of truth offers insight into the normative force carried in the stroke of judgment. For Frege, judgments are a particular type of thought about thinkable contents directed at the world; the act involved in prefixing the judgment-stroke to such a thought produces a re-cognition of that thought as being true. Consequently, being true is a value assigned by the judgment-stroke, which some thinkable contents subsequently possess, while others do not; those that do are always already in the mode of affirming truth in virtue of having this ambiguous logical and epistemic as-structure. The possession of this value assigned by the judgment-stroke functions normatively as a standard governing affirmation, as a metric for judgment and assertion. Thus, for Frege, truth is a normative constraint in the sense that the value carried by the judgment-stroke is a metric for the success or failure of cognitive acts with regard to their putative apprehension of how the world is. Cognitive acts can always be measured or tested against this value given that the question of truth arises for each one.

The combination of these Kantian and Fregean elements furnishes the construct of truth as a normative modality of cognitive acts, and this construct can be developed with the aid of further analyses. Sher (2004), for instance, has recently developed one such concept under a so-called Immanence Thesis (upper-case 'I'). In offering an outline of this thesis and its relevance to the construct of truth as a normative modality of cognitive acts, we will trace some of its Kantian and Fregean roots, and point out some of its non-Kantian, non-Fregean elements. 
5.1. Immanence Thesis. Briefly, we can formulate the Immanence Thesis as the view that truth lies at the juncture of three basic modes of thought:

(i) the immanent mode: the mode of direct engagement with an external subject matter, normally, a structure of objects possessing properties and standing in relations, where the engagement is typically attributive, i.e., consists in the attribution of properties and relations to the objects in the structure or, more generally, in saying that things are thus and so.

(ii) the transcendent mode: the mode of transcending a given thought, or domain of thoughts, in order to reflect upon it, ask questions about it, think immanently about it (attribute properties to it, relate it to other thoughts or to things other than thought), etc.

(iii) the normative or critical mode: the mode of critically evaluating a given object, possibly a thought, relative to some goal, standard, or desideratum.

Truth arises out of these three basic modes of human thought roughly in the following way: Given an immanent thought, $\psi$, the critical, transcendent question 'Is it so as $\psi$ says it is?' arises with respect to $\psi$, and truth is a standard for a positive answer to this question. That is, given an immanent thought, $\psi$, truth is a standard for it being so as $\psi$ says it is (object $x$ has the property $F$ at time $t$, objects $x_{1}, \ldots, x_{n}$ stand in relation $R$, the property $G$ is not a causal power of $x_{1}$, etc.) such that $\psi$ is said to be true iff it satisfies this standard. Now, given the content of the critical-transcendent question concerning $\psi$, a positive answer to it carries us outside $\psi$, into things external to $\psi$, things that $\psi$ is about - "the world," broadlyspeaking. The question is whether the objects $\psi$ is about have the properties, stand in the relations, etc. that $\psi$ attributes to them or, more generally, whether the world is as $\psi$ says it is. That is, it is a question about the relation between a $\psi$ and the world external to $\psi .{ }^{12} \mathrm{We}$ will discuss each of these modes in turn.

5.2. The Immanent Mode. The immanent mode of thought is the mode of attributive thinking, i.e., the mode of attributing properties and relations to objects or saying that things (or the world) are one way or another. This is the mode we are in when we speak in the indicative mood, e.g., when we say that 'der Papst ist ein Junggeselle,' ' $2+2=5$,' 'Pegasus is a flying horse,' 'Anna Karenina committed suicide and so did Sylvia Plath,' 'space is infinite,' 'James Dean lives in the hearts and minds of every Hoosier,' 'something exists,' 'no one knows everything,' etc. It is not the mode we are in when we ask questions, give orders, cry "Ouch!," etc. The concept of IMMANENCE was initially used by the scholastics in cosmological discourse, having taken it from the Latin immanere, meaning inherent in or to remain in; it has since become a term-of-art in numerous philosophical theories, assuming highly diverse meanings. In the $20^{\text {th }}$ century, Quine adapted it to mean speaking from within a theory, or from within an object language, where speaking from within a theory is saying something about how things are, and speaking from within an object language is attributing properties and relations to the objects in its universe of discourse. 
The picture of cognition underlying Sher's Immanence Thesis is broadly Kantian. Accordingly, the mind is both active and passive, both receptive and creative. Knowledge is achieved by an elaborate process of synthesis of input, where both the external environment and the processing mechanisms themselves make substantial contributions to the cognitive output. At some point an external world emerges, with objects, properties, relations, structures, etc.; at another point thoughts arise, including immanent thoughts, i.e., thoughts attributing properties and relations to objects, thoughts attributing structure to domains of objects, etc. Thoughts are, from one perspective, cognitive acts, abstract entities from another. Immanence is a mode of thoughts as cognitive acts, a property of thoughts as objects. The stage of thought is just prior to the assignment of a Kantian modality, or the subjection to a Fregean judgment-stroke. Thoughts need not assume an assertoric (or problematic, or apodeictic) modality, but they are the kind of thing that is ready to assume it. Thoughts can be struck by the judgment-stroke, though need not be; they do attach to the prior, "content" stroke (or "horizontal"), which signals their readiness (in principle) to assume the former attachment.

While the cognitive framework of the Immanence Thesis is broadly Kantian, it is not specifically Kantian. For instance, the thesis is committed neither to Kant's claim that the external input is exclusively empirical, nor to the claim that the processing mechanisms are governed by a fixed set of categories (let alone the specific Kantian categories). The cognitive framework itself is transcendental, and as such it satisfies both Kant's injunction against traditional metaphysics and Frege's injunction against identifying philosophy with empirical psychology. Furthermore, the introduction of a category of immanent thought is designed to introduce a domain of (potential) truth bearers; but although the paradigm cases of truth-bearers are roughly the same for both Kant and the Immanence Thesis, the range of truth-bearers recognized by the latter is far broader than in either Kant or Frege's views. Kant, for example, excluded philosophical thoughts (including transcendental thoughts) and logic (in the narrow Kantian sense of the word) from the domain of truth-bearers, while the Immanence Thesis includes these in the range of immanent thoughts emerging from the cognitive process of synthesizing input. And while Frege, for his part, denied truth bearers that were not sufficiently serious (e.g., assertions made by actors on a stage), the Immanence Thesis does not. Nor does it exclude non-literal thoughts (e.g., ironic or metaphorical thoughts) from the category of truth-bearer. This fact is extremely important to stress, because the expression of thought in natural language is deeply structured by metaphor, blending, metonomy, humor, and construal (Fauconnier and Turner 2002), and very rarely consists in 'snow is white' discourse. Furthermore, the unit of immanent thought is not restricted to thoughts expressed by single sentences: theories and massively complex hypotheses, for example, can (and typically do) have the property of immanence and would not be excluded, as a result, from being (potential) truth-bearers. But while the category of immanent thoughts is broad, it cannot be viewed as a mere grammatical category, e.g., the category of indicative thoughts. The Immanence Thesis allows the possibility that certain thoughts in the indicative mood - thoughts appearing attributive - are in fact not 
attributive. For example, it is compatible with (though not partial to) the expressivist claim that moral (indicative) thoughts express attitudes or emotions toward, rather than attribute moral properties to, their subjects.

5.3. The Transcendent Mode. While the immanent mode supplies a domain of potential truth-bearers, it does not create, all by itself, suitable conditions for truth to arise. The catalyst of truth is a critical question about immanent thoughts, i.e., a question transcendent to immanent thoughts, a question asked in the transcendent mode of thought. Given an immanent thought $\psi$, the critical transcendent question giving rise to truth - the so-called "question of truth" - is the question: "Are things as $\psi$ says they are?" If $\psi$ says that $x_{1}$ does not have the property $F$, the question of truth is: "Does $x_{1}$ not instantiate the property $F$ ?"; if $\psi$ says that $x_{1}$ stands in relation $R$ to $x_{2}$, the question of truth is: "Does $x_{1}$ actually stand in $R$ to $x_{2}$ ?"; if $\psi$ says that there are black holes (i.e., $\{x: x$ is a black hole $\}$ is not empty) the question of truth is: "Are there black holes?" ("Is $\{x: x$ is a black hole $\}$ not empty?"); and so forth. The question of truth is not the only critical-transcendent question concerning immanent thoughts. Other questions include: "Does $\psi$ conflict with another immanent thought $\psi^{\prime}$ (or with a designated set of immanent thoughts)?"; "Can it be determined (say, by empirical means) whether or not $x_{1}$ has the property $G$ ?"; "Do people in community $\kappa$ believe that $x_{1}$ has the property G?"; and so forth. Such questions give rise to notions (and standards) of coherence, verifiability, communal belief, etc. But the question giving rise to truth is the first critical-transcendent question raised above (and its various instances): "Are things as $\psi$ says they are?"

The notion of transcendence used in this account is altogether different from Kant's notion. For Kant, transcendent thinking takes place outside the cognitive process generating genuine knowledge. Transcendent thought is neither constrained by the external world nor subject to conceptual constraints whose sources are information processing mechanisms; instead, it is directed at the world "as it is in itself" ('Noumenon') regardless of our limitations, i.e., it transcends the boundaries of human cognition.

The transcendent mode affirmed by the Immanence Thesis is of a different kind. Transcending a thought is neither directing one's cognitive gaze at 'things-inthemselves,' nor neglecting the inner constraints of human cognition. The very dichotomy of phenomena and noumena (appearances and things-in-themselves) is foreign to the Immanence Thesis, as is the idea of an absolute viewpoint - the 'View from Nowhere,' in Nagel's terminology. Transcending, in the sense of the Immanence Thesis, is akin to ascending to a Tarskian meta-language - a level of thought which enables us to view another level of thought while remaining bound by the usual constraints on human cognition. Using the well-known metaphor of Neurath's Boat, we may say that transcending $\psi$ is finding a perspective from which to view $\psi$, a perspective on the boat rather than outside it. Such transcendence is not necessarily fixed or absolutely hierarchical: we transcend 
philosophy to view it from a sociological (or psychological) standpoint, and we transcend sociology (or psychology) to view it from a philosophical standpoint.

5.4. The Normative or Critical Mode. As we have already discussed, the question of truth raises the need for a norm of truth, a standard for giving a positive answer to the "question of truth" as it applies to immanent thoughts. It is at this stage that a normative conception is created and an alethic property identified. ${ }^{13}$ An immanent thought $\psi$ has the property of truth iff the question of truth as it applies to it has a positive answer, i.e., iff it satisfies the standard of truth. What satisfying this standard amounts to is a question we will attend to momentarily. But first let us note that to attribute truth to an immanent thought $\psi$ is to express another thought, $\psi^{\prime}$, where $\psi^{\prime}$ partakes in all the three modes characteristic of truth: (i) $\psi^{\prime}$ is an immanent thought: it attributes a property, truth, to an object, $\psi$; (ii) $\psi^{\prime}$ is a transcendent thought: it views a thought, $\psi$, from a point of view external to it; and (iii) $\psi^{\prime}$ is a normative thought: it says that $\psi$ satisfies the norm or standard of truth, i.e., that the normative question, "Is it so as $\psi$ says it is?" has a positive answer.

The structure of immanent thoughts, along with the content of the question of truth, suggest what a standard of truth might amount to. If $\psi$ attributes property $F$ to object $x_{1}$, and the question of truth is whether $x_{1}$ has the property $F$, then a standard of truth for $\psi$ has to do with the conditions under which $x_{1}$ has the property $F$. More generally, a standard of truth involves a systematic relation between the attribution of properties to objects and the conditions under which those objects possess those properties; Sher (2004: 27) submits that the systematic relation involved in a standard of truth is a correspondence standard. From the point of view of the Immanence Thesis, however, this relational standard is multidimensional, and a "complete" account of it must address its multiple dimensions. We will not be able to list the many dimensions of this standard here; instead we will point out a few questions that suggest its multi-dimensionality:

(i) There is the question of the conditions under which objects of different kinds possess properties of different types (e.g., the conditions under which physical objects possess physical properties, the conditions under which mathematical objects possess mathematical properties, the conditions under which humans possess biological properties versus those under which they possess economic properties).

(ii) There is the question of how names and predicates of various kinds denote objects and properties of the respective kinds (e.g., the way a proper name denotes a person as opposed to the way a numeral denotes a number).

(iii) There is the question of how context affects the standard of truth (e.g., given the thought that a Russian woman named Anna Karenina committed suicide at a certain time in a certain location, the question whether things are as this thought says they are can be asked either with respect to the reality of Tolstoy's novel or with respect to the reality of our (and our ancestors') lives). 
(iv) There is the question of how a positive answer to the question of truth connects different elements in the (broadly Kantian) cognitive process outlined above (e.g., how the stage of unstructured input is systematically connected to that of a world of objects, how structures of objects possessing relatively simple properties like mass and position are systematically connected to thoughts employing highly complex concepts like CAUSE or LAUGHTER).

To sum up: we have been promoting two complementary thoughts that hark from the exploitation of Kantian and Fregean elements, respectively, in order to develop a more general analysis that goes beyond a merely locutionary treatment: first, that the alethic mode of actuality is the mode from which immanent cognition emerges, and second, that the immanent cognitions emerging thereof must respect certain normative constraints on the systematic relationship between this mode and the ways in which the world is. From these two elements a construct of truth as a normative modality of cognitive acts is generated, and is developed by Sher's (2004) Immanence Thesis. Truth, according to this view, provides a metric for the success or failure of immanent thought relative to a particular question, the question of truth.

\section{Alethic and epistemic modalities}

In developing this construct of truth as a normative modality of cognitive acts, we have interpreted Kant (and Frege, to some extent) as having motivated an account of the cognitive and epistemic nature of truth: truth plays a fundamental role in the context of synthesizing cognitive states into judgments in the alethic mode, ultimately leading to the possibility of knowledge. Consequently, this construct is developed in a richly epistemic context. It is important to note, however, that 'epistemic' is not being used in the sense of warranted assertibilist or similar epistemic or antirealist theories of truth - Pierce's, Putnam's, or Walker's, for example. Rather, the sense of 'epistemic' is the one typically used by linguists in discussing the concept of EPISTEMIC MODALITY - a notion closely related to its alethic counterpart. In the remaining space, we want to suggest that there is a mutually beneficial direction for future research between the sort of philosophical analysis of the alethic mode of actuality that we have developed here, and the linguistics research on the concept of EPISTEMIC MODALITY.

The concept of EPISTEMIC MODALITY has been described in numerous different ways, but central to each description is the cognizer's relation or orientation to her immanent cognitions. For instance, Nuyts characterizes it as "[A]n estimation of the likelihood that (some aspect of) a state of affairs is/has been/will be true (or false) in the context of the possible world under consideration (Nuyts 2001: 22), and Bybee and Fleischman write that, "Epistemics are clausal-scope indicators of a speaker's commitment to the truth of a proposition" (Bybee and Fleischman 1995: 6); see also Palmer (2001: 8). Consequently, we can put the main difference between these two types thus: whereas the alethic use of modals concerns the 
possibility, actuality, and necessity of subjects' judgments, the epistemic use of modals primarily concerns those subjects' judgments of possibility, actuality, and necessity.

Interest in the concept of EPISTEMIC MODALITY has increased dramatically in cognitive science and linguistics, but the same cannot be said for the mode by which judgments or thoughts can bear truth. This raises a question about the extent to which this illocutionary role of the concept of TRUTH can be fully explained by the alethic mode of actuality. In linguistics, there is typically a sharp distinction between the alethic and epistemic modalities, and a subsequent attempt to dismiss the alethic modalities by reducing them to a subset of the epistemic ones. Palmer, for instance, writes, "Alethic modality has been the main concern of logicians, but it has little place in ordinary language. ... It seems likely that no clear distinction is recognized by native speakers between the alethic use and the epistemic use [of modals]" (Palmer 1990: 6). Sweetser concurs, writing that, "I am fully in agreement with Palmer when he says that the so-called alethic modalities (however useful in formal logic) play a negligible role in naturallanguage semantics" (Palmer 1990: 58-9). In our view, we do not sharply distinguish between the two, and suggest that attempts to do so either prove ultimately fruitless, or end up with an impoverished understanding of truth. ${ }^{14}$

There are at least three reasons for why it would be hasty to conclude - as Lyons, Palmer, Sweetser, and other linguists do - that the alethic mode of actuality can be reduced to or fully subsumed under the epistemic mode. One reason has to do with the history of the concept of MODALITY. The vast majority of linguists and cognitive scientists no longer include the mode of actuality among the alethic modalities - only possibility and necessity are considered - because they pass over the thought of Leibniz and Kant, and typically only go back as far as Von Wright's (1951) seminal work as the historical point of departure. Yet, the failure to maintain Kant's threefold distinction between modes of the logical functions of judgment seems to cause the alethic modalities seem to lose their place in the analysis of natural language. By revisiting some of this history in order to ground the distinction between possibility and actuality, the putative reduction of the alethic to epistemic modality becomes an open question again. A second, more important reason is that an account which uses epistemic modality as the sole basis for capturing the nature of truth must remain faithful to the syntactically unexpressed illocutionary role that truth plays in assertion and judgment; yet this constraint makes it unclear what mode - alethic or epistemic - a given cognizer is using on a given usage-event. Thus, assertions frequently exhibit logical and semantic ambiguity between alethic and epistemic modes of actuality. As such, it is not obvious that one modality can be subsumed under the other, for both seem to be heavily contributing to the illocutionary role of the concept of TRUTH. ${ }^{15}$ This point is nicely captured by Nuyts, whose remark not only lends further support to the fact that overtly locutionary treatments cannot be comprehensive, but also suggests that the mode of actuality is a foundational category of cognition and conceptualization: 
[I]t is plausible to assume ... that epistemic modality is not a specifically linguistic category. Estimations of the degree to which states of affairs are true of the world are no doubt an essential ingredient of any kind of human perception and action, as the veridicality of a human's understanding of the world is critical for her adequate functioning in it. So, epistemic evaluations are probably a basic category of human conceptualization in general, emerging from high-level metarepresentational operations over knowledge ... Hence, an investigation of them can probably not be limited to a purely linguistic description, but will also require a concern with the conceptual systems from which they derive.

(Nuyts 2001: 23) ${ }^{16}$

From this second reason, we can advance a third reason for resisting the reduction of alethic mode of actuality to its epistemic counterpart. As noted above, epistemic modality crucially concerns a cognizer's orientation to her immanent cognitions; yet, if we take Frege's analysis of truth as a norm of judgment seriously, then we have a reason for thinking that - on the contrary - a cognizer's orientation to her immanent cognitions is made possible by a prior, more basic orientation to the world. Accordingly, the world stands to a cognizer's orientation toward it as a source of friction or regulation governing thinkable contents; by opening herself up to this source of friction, to the possibility of error or mistake, the Fregean cognizer wins for herself an environment from which epistemic modality is itself derivative.

In sum: generally, an advantage to the sort of analysis developed here is that it makes possible mutually beneficial contact between traditional philosophical considerations and the burgeoning body of research about modality in linguistics. For instance, philosophical analyses can benefit from utilizing the resources of research on the cognitive basis of language as a way of dealing with the various constructions, idioms, and alternative alethic locutions mentioned in $\S 2$; research on epistemic modality stand to likewise benefit by better understanding the role and import of the concept of TRUTH by appealing to the alethic mode of actuality and Immanence Thesis laid out in $\S 5$. Fleshing out this contact will require a much fuller treatment, of course, and we can only here point out the direction of this promising line of research. But doing so will provide the opportunity for an interestingly different perspective on the illocutionary role of the concept of TRUTH.

\footnotetext{
${ }^{1}$ The varieties of redundancy theory, e.g., Ayer (1946); Ramsey (1927); White (1957); Williams (1976) - which allege that the role or function of the predicate 'is true' is in some sense superfluous, or that it is merely an indirect or stylistic way of talking about, or appraising, assertions - certainly constitute another example. Some might be concerned to construe Tarski's work (e.g., 1944, 1956) as falling within the scope of this overtly locutionary treatment of truth, although it need not be.
} 
${ }^{2}$ Consider the cognate predicate in Spanish - 'es la verdad' - in this last example. As Serrano (2001) indicates, 'la verdad' is used as a discourse marker that serves at least two functions, which are primarily pragmatic and discursive in nature: introducing a response and supporting a previous argument. With regard to the first, "The marker la verdad introduces an assertive response which is not expected by and possibly contrary to the position of the interlocutor, acting as an reaffirmative purpose resulting from the grammaticalization of its lexical meaning" (Sorreno 2001: 105). This is, of course, only one result; but in amassing such comparative linguistic data, one begins to realize that Horwich's claim - namely, that all uses of the truth predicate are for generalizing over unarticulated propositions - is either simply uninformed or unduly restrictive.

${ }^{3}$ With regard to the equivalence of left and right sides of the various biconditional $\mathrm{T}$-schemas, Frege's point is not that truth has no role in assertoric or doxastic practice or is thereby eliminable, but that it has a role even when it is not explicit; truth is implicit in every judgment and assertion.

${ }^{4}$ Concerning (i), this is Kant's nominal definition of truth. Consistent with his general account of definition, Kant felt no compulsion to articulate what more this relation amounts to. For a few further points with regard to (ii), see Sher (1998-9: 138-42); Sher (2004: 8-18).

${ }^{5}$ One might recognize contemporary analogues to Kant's account of the production of cognition by means of the co-operative union of receptivity and spontaneity. For example, in his seminal essay 'Fictive motion in language and ception,' Talmy (2000: 99-177); see also Goldstone and Barsalou (1998) posits a single unified domain, dubbed 'ception', which exploits bottom-up and top-down cognitive processing of perceptual and conceptual information to produce representations. Although Talmy's view is far more complicated, Kantian analyses might be understood as suggesting that, in cognition about the world, immediate percepts and mediate concepts are united to 'ceptually' represent objects.

${ }^{6}$ What Kant understood by a 'disjunctive judgment' - that is, a compilation of all mutually disjoint possibilities with respect to a given subject matter - differs from that used in modern logics and formal semantics.

7 For further discussion of how the purely formal status of modality sets it apart from the three other groups of logical functions, see Greenberg (2001: 137-57).

${ }^{8}$ Our explication of his analysis corroborates the exegesis of Hanna (2000: 233-35) and Van Cleve (1999: 214-16) against those who use Kant's response to the Diallelus to argue that he was committed to some version of the coherence theory of truth.

${ }^{9}$ It is worth noting that Frege did not dress the concept of JUDGMENT in Kantian terminology - that is, as a synthesis of cognitive states that may possess the relational property of agreement such that extant objects are re-cognized to be as they actually are. Greimann succinctly puts this difference thus: "To judge is ... not to unite ideas, but to acknowledge something which is already united as true. In particular, the basic cognitive operation is, for Frege, not 'to say something of something,' but 'to judge something as true"' (Greimann 2000: 220).

${ }^{10}$ The advantage in retrieving and exploiting only a few elements from the analyses of Kant and Frege lies in the fact that doing so carries no further commitment to other aspects of their respective views - aspects which may be controversial, exegetically treacherous, or in conflict with our own analysis. For instance, we can slough off the metaphysical distinction between the realm of appearance and the realm of things-in-themselves, the Kantian categories, Kant's restriction of correspondence to empirical reality, and the analytic-synthetic distinction, as well as Frege's view of truth as the reference of sentences or sentential sense designating 'The True,' his restriction of the 'laws of truth' to logical laws, his objections to the correspondence theory of truth, his commitment to a 'third realm,' etc. Further, we need not relate to the Fregean conclusion that truth is a primitive concept - semantic or otherwise; for from the claim that truth is undefinable, it does not follow that truth is an unexplicable, or primitive sui generis concept. The concept of truth may turn out to just be inordinately complex for the purposes of giving a definition, which is not to rule out the possibility that a complex theory or family of theories can explain its nature; see Sher (1998-9), (2004).

${ }^{11}$ In following Kant and Frege, we accept that the progression of an analysis of the construct of truth as a normative modality, and of a cognitive account of the nature of truth more generally, may crucially depend on there being a viable theory of cognitive acts. And while the paradigmatic 
cognitive act has traditionally been the judgment, we do not rule out that other cognitive acttheoretic accounts may be able to displace the centrality of judgment, e.g., Fauconnier's (1985) theory of mental space construction.

12 Consequently, for an immanent thought to be true, the relation must exhibit some positive correlation (not necessarily isomorphism) between what it says (literally or non-literally) and how things are. Many philosophers have taken this relation to be one of correspondence - a view held by at least one of the authors.

${ }^{13}$ This second main aspect of the Immanence Thesis raises a question about the place of virtue epistemology in characterizing the construct of truth as a normative modality of cognitive acts, e.g., Holt (2002); Williams (2002). If making correct attributions in immanent cognition (viz., seeing aright, perceiving veridically, thinking correctly, and asserting truly) is symptomatic of strength of character in a way that requires truth to be normative in the further sense of being an Aristotelian virtue, then explaining the illocutionary role of truth may turn out to be a much larger and more difficult project than many contemporary analyses have acknowledged.

${ }^{14}$ It is not uncommon to find researchers faithfully taking the views of Palmer and Lyons as putatively established. For example, Nuyts concludes that it is not surprising to find an absence of any formal grammatical distinction between the two modes, because "As far as the semantics of natural language goes, 'truth' is always truth for the language user, hence truth in his/her knowledge of the world" (Nuyts 2000: 28). We sympathize with this conclusion; but unfortunately, no justification for such a premise is offered. Worse, attempts at pluralist approaches to the concept of TRUTH that relativize to idiolects and individual speakers face sobering challenges (Swoyer 1982); (Wright 2004).

15 As Papafragou (2000) has shown, the semantically encoded content of modal locutions underdetermines the interpretations that may obtain during utterance comprehension. Perhaps it will be no surprise, then, that the concept of MODALITY inherits some of the familiar content/act ambiguity, and further, that attempts to parse this concept into these two modes fundamentally informs the debate between the two different ways of interpreting Frege's judgment-stroke mentioned previously.

${ }^{16}$ See also Papafragou (2000).

\section{References}

Ayer, A.J. (1946) Language, Truth, and Logic, New York: Dover Publishing. Bell, D. (1979) Frege's Theory of Judgment, Oxford: Clarendon Press.

Brandom, R. (1994) Making it Explicit, Cambridge: Harvard University Press.

-- (2002) 'Explanatory versus expressive deflationism about truth', in R. Schantz (ed.) What is Truth?, Berlin: De Gruyter, pp. 103-19.

Bybee, J.L. and Fleischman, S. (1995) Modality in Grammar and Discourse, Amsterdam: John Benjamins Publishing Company.

Fauconnier, G. (1985) Mental Spaces, Cambridge: MIT Press.

Fauconnier, G. and Turner, M. (2002) The Way We Think: Conceptual Blending and the Mind's Hidden Complexities, New York: Basic Books.

Frege, G. (1879/1967) 'Begriffsschrift, a formula language, modeled upon that of arithmetic, for pure thought', in J. van Heijenoort (ed.) From Frege to Gödel: A Source Book in Mathematical Logic, Cambridge: Harvard University Press, pp. $1-82$.

-- (1892) 'Über Sinn und Bedeutung', Zeitschrift für Philosophie und Philosophische Kritik, 100: 25-50.

-- (1906/1979) Nachgelassene Schriften, trans. P. Long and R. White, Oxford: Basil Blackwell. 
-- (1918/1956) 'The thought: A logical inquiry', trans. A.M. and M. Quinton, Mind, 65: 289-311.

-- (1918/1977) Logical Investigations, ed. and trans. P. Geach, Oxford: Oxford University Press.

Goldstone, R.L. and Barsalou, L.W. (1998) 'Reuniting perception and conception', Cognition, 65: 231-62.

Greenberg, R. (2001) Kant's Theory of a priori Knowledge, University Park: University of Pennsylvania Press.

Greimann, D. (2000) 'The judgment-stroke as a truth-operator: A new interpretation of the logical form of sentences in Frege's scientific language', Erkenntnis, 52: 213-38.

Grover, D. (1992) A Prosentential Theory of Truth, Princeton: Princeton University Press.

Hanna, R. (2000) 'Kant, truth, and human nature', British Journal for the History of Philosophy, 8: 225-50.

Holt, L. (2002) Apprehension: Reason in the Absence of Rules, Burlington: Ashgate Publishing Company.

Hornsby, J. (2001) 'Truth: The identity theory', in M.P. Lynch (ed.) The Nature of Truth: Classic and Contemporary Perspectives, Cambridge: MIT Press, pp. 66381.

Horwich, P. (1990) Truth, Oxford: Basil Blackwell.

Kant, I. (1787/1996) The Critique of Pure Reason, trans. W. Pluhar, Indianapolis: Hackett Publishing Company.

-- (1800/1992) Lectures on Logic, ed. and trans. J.M. Young, Cambridge: Cambridge University Press.

Nuyts, J. (2001) Epistemic Modality, Language, and Conceptualization: A Cognitive-Pragmatic Perspective, Amsterdam: John Benjamins Publishing Company.

Palmer, F.R. (1990) Modality and the English Modals, London: Longman Press.

-- (2001) Mood and Modality, Cambridge: Cambridge University Press.

Papafragou, A. (2000) Modality: Issues in the Semantics-Pragmatics Interface, Oxford: Elsiever Science.

Ramsey, F.P. (1927) 'Facts and propositions', Proceedings of the Aristotelian Society (Suppl.), 7: 153-70.

Ricketts, T. (1996) 'Logic and truth in Frege', Proceedings of the Aristotelian Society (Suppl.), 70: 121-40.

Serrano, M.J. (2001) 'The socio-communicative function of two discourse markers in Spanish', Estudios de Sociolingüistica, 2: 101-22.

Sher, G. (1998-9) 'On the possibility of a substantive theory of truth', Synthese, 117: 133-72.

-- (1999) 'Is logic a theory of the obvious?', European Review of Philosophy, 4: 207-38.

-- (2004) 'In search of a substantive theory of truth', Journal of Philosophy, 101: 5-36.

Sweetser, E. (1990) From Etymology to Pragmatics, Cambridge: Cambridge University Press. 
Swoyer, C. (1982) 'True for', in J. Meiland and M. Krausz (eds) Relativism: Cognitive and Moral, Notre Dame: University of Notre Dame Press, pp. 84-108. Talmy, L. (2000) Toward a Cognitive Semantics, vol. 1, Cambridge: MIT Press.

Tarski, A. (1944) 'The semantic conception of truth', Philosophy and Phenomenological Research, 4: 341-76.

-- (1956) Logic, Semantics, and Metamathematics, trans. by J. H. Woodger, Indianapolis: Hackett Publishing Company.

Van Cleve, J. (1999) Problems from Kant, New York: Oxford University Press.

Von Wright, G.H. (1951) An Essay in Modal Logic, Amsterdam: North Holland.

White, A.R. (1957) 'Truth as appraisal', Mind, 66: 318-30.

Williams, B. (2002) Truth and Truthfulness: An Essay in Geneology, Princeton: Princeton University Press.

Williams, C.J.F. (1976) What is Truth?, Cambridge: Cambridge University Press.

Woleński, J. (2003) 'Psychologism and metalogic', Synthese, 137: 179-93.

Wright, C.D. (2005) 'On the functionalization of pluralist approaches to truth', Synthese, 145: 1-28. 